\title{
Genetic variants and magnetic resonance imaging measures in multiple sclerosis: a systematic review
}

\author{
Jan K. Nowak', Izabela Guzikowska-Ruszkowska ${ }^{2}$, Jadwiga Łopaciuch ${ }^{3}$, Wiesława Jankowska ${ }^{3}$, \\ Ewa Piotrowska ${ }^{4}$, Ewa Dziedzic-Szeszuła ${ }^{5}$, Kinga Kapecka ${ }^{6}$, Jarosław Walkowiak ${ }^{1}$ \\ ${ }^{1}$ Department of Pediatric Gastroenterology and Metabolic Diseases, Poznan University of Medical Sciences, Poland \\ ${ }^{2}$ Department of General Radiology and Neuroradiology, Poznan University of Medical Sciences, Poland \\ ${ }^{3}$ Department of Biology and Medical Parasitology, Poznan University of Medical Sciences, Poland \\ ${ }^{4}$ Department of Clinical Pathomorphology, Poznan University of Medical Sciences, Poland \\ ${ }^{5}$ Department of Ophthalmology, Poznan University of Medical Sciences, Poznan, Poland \\ ${ }^{6}$ Department of Neurology, Poznan University of Medical Sciences, Poland
}

\section{ABSTRACT}

Introduction. Although environmental factors play the major role in the etiopathogenesis of multiple sclerosis (MS), genetic factors are implicated as well. We aimed to summarize the current knowledge on the relationship between genetic variants and magnetic resonance (MR) imaging measures in MS.

Material and Methods. A systematic review. In December 2016, Scopus (since the year 1980; including MEDLINE) was searched for studies meeting predefined criteria designed to identify articles regarding: multiple sclerosis, genetic variants, and MR imaging. These were then analyzed to identify publications linking polymorphisms and MR findings.

Results. The search yielded 290 items; 26 were included in the final analysis. Two genome-wide association studies (GWAS) and two projects employing panels of a few dozen of genes of interest provided most of the data. The other publications concerned no more than 5 genes at a time. Twenty studies reported positive findings. The relationship between HLA-DRB1*15:01 or BDNF rs6265 (Val66Met) and the radiologic course of MS was not consistent across the studies. An intersection of the results of the two GWAS yielded: OPCML (rs11223055), PTPRD (rs1953594), and WWOX (rs11150140, rs1116525) (brain atrophy) as well as CDH13 (rs692612) and PLCB1 (rs6118257) (lesion load).

Conclusions. Genetic variants were shown to correlate with MS-related brain atrophy and lesion load. Further research in the field is required.

Keywords: brain, spinal cord, cortical, atrophy, lesion, polymorphism, snp, haplotype, imaging.

\section{Introduction}

Although environmental factors play the major role in the development of multiple sclerosis (MS; OMIM: 126200), genetic factors are implicated as well. Firstly, variants in human leukocyte antigen (HLA) complex genes are known to confer susceptibility to MS.
The strongest evidence in this respect exists for the HLA-DRB $1 * 15: 01$ haplotype. Secondly, over a hundred single-nucleotide polymorphisms not related to HLA system are also known to influence the risk and/or course of this disease [1]. A number of studies specifically investigated the potential associations 
between genetic variants and measures of central nervous system involvement in magnetic resonance (MR) imaging. We aimed to systematically review the literature on this topic and present the main data in a legible format.

\section{Material and Methods}

On December $8^{\text {th }}, 2016$, Scopus (Elsevier, Amsterdam, Netherlands; includes MEDLINE [2]) was queried with the following term: "TITLE (multiple sclerosis) AND TITLE-ABS-KEY (lesion OR lesions OR hyperintensity OR hyperintensities OR hyperintense OR hypointensity OR hypointensities OR hypointense OR enhancing OR enhanced OR enhance) AND TITLE-ABS-KEY (rs* OR variant $O R$ variants $O R$ polymorphism $O R$ polymorphisms)." All types of documents were thus searched without a time limit. The 290 results were exported and further analyzed after excluding one item published before the year 1980, when magnetic resonance was first used in a clinical setting; although the first studies of genetic polymorphisms in MS were performed later, we did not filter our results further on the basis of the year published. All the entries were written in English. After screening titles and abstracts for information confirming that the studies investigated genetic variants, 91 of them were selected for further assessment. Among these, 26 reported investigating a possible link between genetic variation and radiological findings in the abstract; these were chosen for the final analysis (there were no duplicates). One of the articles was not included since the full text could not be obtained and imaging-related results in the abstract were unclear [3]. Another article was identified as relevant in references of the chosen studies [4]. We followed the approach proposed in the Preferred Reporting Items for Systematic Reviews and Meta-Analyses (PRISMA) statement [5].

\section{Results}

Out of 26 studies, 20 found relationships between genetic variants and radiological findings in MR imaging of the central nervous system (Table 1).

The two genome-wide association studies (GWAS) provided a wealth of data $[8,19]$. Of special interest are also the works by Sombekke et al., in which variants found in $44 \mathrm{MS}$-related genes were analyzed in the context of MR findings [14], and by Inkster et al., who focused on genes involved in epigenetic regulation [12]. The relationships between one or more HLA haplotypes and MR measures were searched for by seven non-GWAS studies. The remaining studies focused on particular genes of interest, of which most commonly researched were BDNF and CCR5. The methods of MR data acquisition and image method analysis varied between the studies, as did characteristics of patient groups.

None of the SNPs that were top-rated by the study of 44 genes by Sombekke et al. was found on the list of MR parameter covariates by Baranzini et al. BTNL2 rs2076530 associated with MS susceptibility, but not MR measures. None of the findings from studies of individual genes (GRIN1, BDNF, IRF5, PCK1, CCL5, CCR5, SIRT4, HDAC11, HDAC9) was replicated by Baranzini et al. The above-listed genes were also missing from the list of 67 genes correlating with MR measures in all cerebral regions of interest in the two recruitment centers of GWAS by Matsushita et al. An intersection of the list by Matsushita et al. with the regression correlate list by Baranzini et al. yielded: OPCML (rs11223055), PTPRD (rs1953594), and WWOX (rs11150140, rs1116525) (Baranzini et al.: brain atrophy) as well as CDH13 (rs692612) and PLCB1 (rs6118257) (lesion load). The relationship between BDNF rs6265 (Val66Met) and the radiologic course of MS was not consistently replicated across the studies. While this was also true for $H L A-D R B 1 * 15: 01$, the recent evidence is convincing [6]. Overall, few positive findings of the reported studies were consistent.

\section{Discussion}

This brief systematic review gathered the data relating genetic variants to MR correlates of neurological lesions in MS. Any comparison of the included studies should consider the fact that MS diagnostic criteria constantly evolve [32]. MR imaging was featured in the clinical criteria in the year 2001, then reviewed in 2005 and 2010. For instance, the latest revision of McDonald criteria permit for an earlier MS diagnosis, but at the cost of the specificity. The work to further improve the guidelines is ongoing [33].

The association of MR measures in MS patients and CDH13, PLCB1, PTPRD, OPCML, and WWOX polymorphisms listed above warrants additional study. In conclusion, genetic variants were shown to correlate with MS-related brain atrophy and lesion load. 


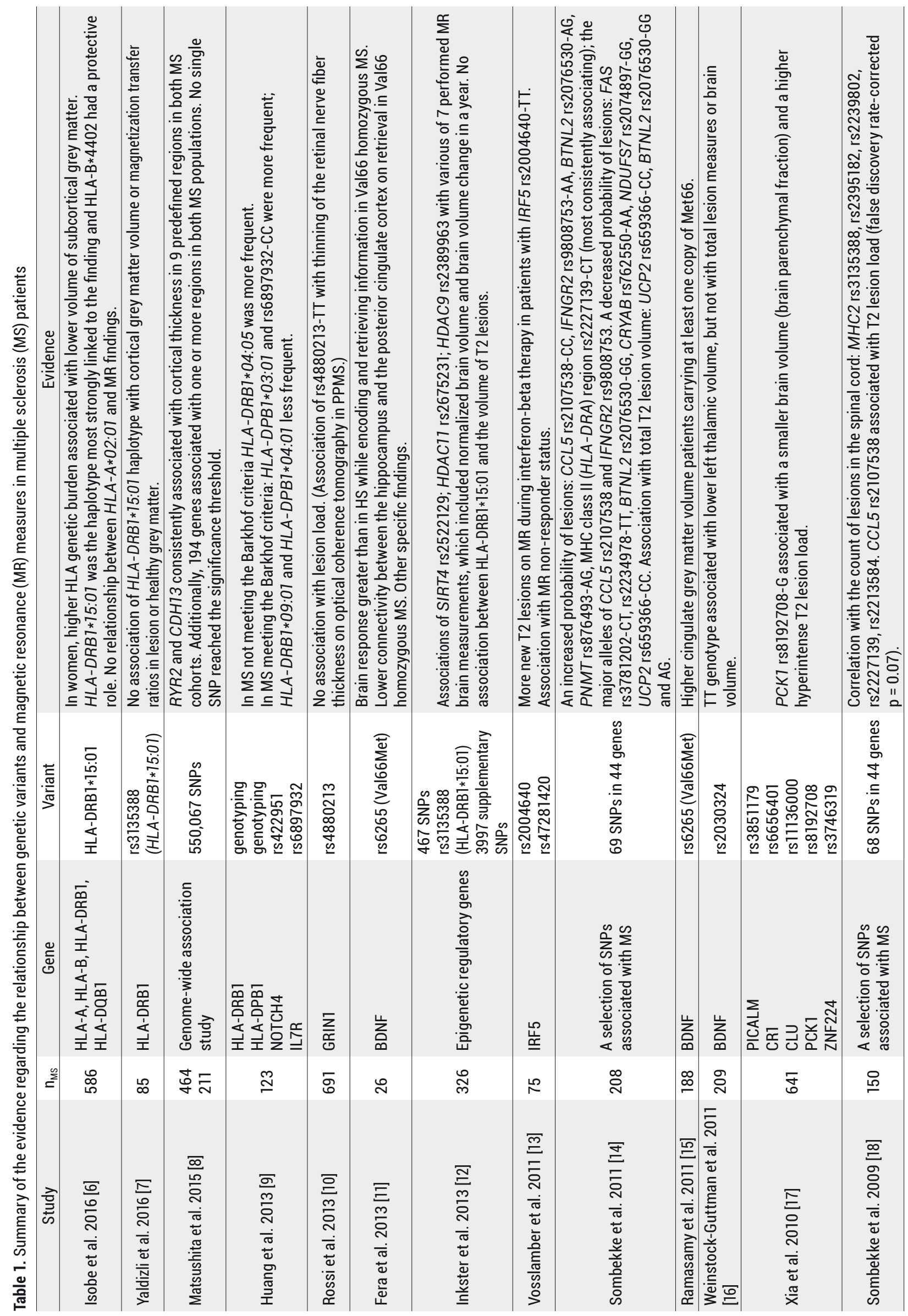




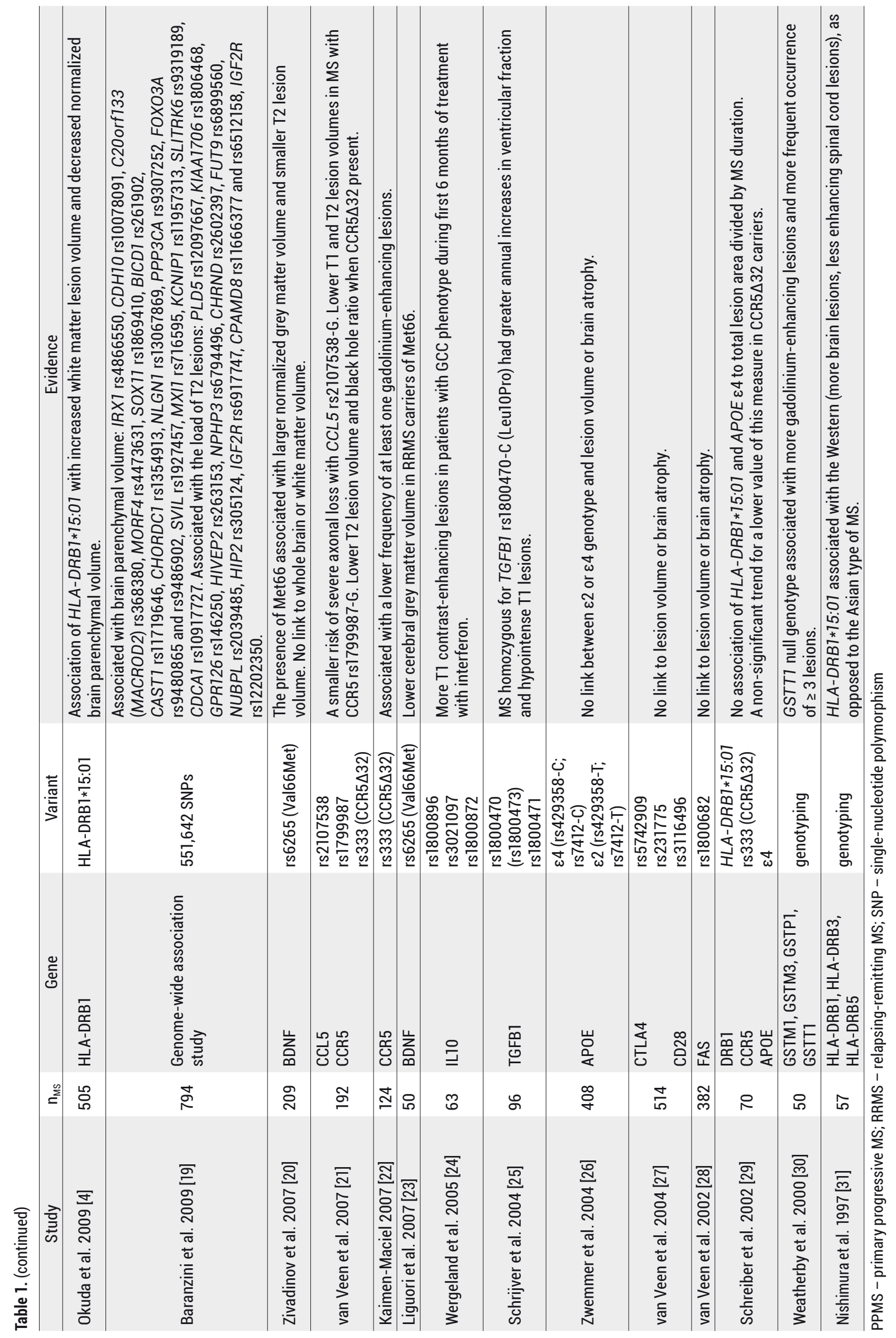


Acknowledgements

\section{Conflict of interest statement}

The authors declare no conflict of interest.

\section{Funding sources}

There are no sources of funding to declare.

\section{References}

1. Olsson T, Barcellos LF, Alfredsson L. Interactions between genetic, lifestyle and environmental risk factors for multiple sclerosis. Nat Rev Neurol. 2016. doi:10.1038/ nrneurol.2016.187.

2. Scopus Content Coverage Guide. 2016. https://www. elsevier.com/_data/assets/pdf_file/0007/69451/scopus_content_coverage_guide.pdf [accessed on December $\left.16^{\text {th }}, 2016\right]$

3. Allam M, Helmy H, Soliman R, Ali N, El-Shafy S. Association of Interleukin-1 Gene Polymerphism and Multiple Sclerosis. Egypt J Neurol Psychiatry Neurosurg. 2014;51:45-51.

4. Okuda DT, Srinivasan R, Oksenberg JR, Goodin DS, Baranzini SE, Beheshtian A et al. Genotype-Phenotype correlations in multiple sclerosis: HLA genes influence disease severity inferred by 1HMR spectroscopy and MRI measures. Brain J Neurol. 2009;132:250-9.

5. Moher D, Liberati A, Tetzlaff J, Altman DG, The PRISMA Group. Preferred Reporting Items for Systematic Reviews and Meta-Analyses: The PRISMA Statement. PLoS Med. 2009;6:e1000097.

6. Isobe N, Keshavan A, Gourraud P-A, Zhu AH, Datta E, Schlaeger $\mathrm{R}$ et al. Association of HLA Genetic Risk Burden With Disease Phenotypes in Multiple Sclerosis. JAMA Neurol. 2016;73:795.

7. Yaldizli Ö, Sethi V, Pardini M, Tur C, Mok KY, Muhlert $\mathrm{N}$ et al. HLA-DRB*1501 associations with magnetic resonance imaging measures of grey matter pathology in multiple sclerosis. Mult Scler Relat Disord. 2016;7:47-52

8. Matsushita T, Madireddy L, Sprenger T, Khankhanian P, Magon S, Naegelin $Y$ et al. Genetic associations with brain cortical thickness in multiple sclerosis: DNA variation affects cortical thickness in MS. Genes Brain Behav. 2015;14:217-27.

9. Huang J, Isobe N, Matsushita T, Yoshimura S, Sato S, Yonekawa $T$ et al. Distinct genetic profiles between Japanese multiple sclerosis patients with and without Barkhof brain lesions. Clin Exp Neuroimmunol. 2013;4:173-80.

10. Rossi S, Studer V, Moscatelli A, Motta C, Coghe G, Fenu $G$ et al. Opposite Roles of NMDA Receptors in Relapsing and Primary Progressive Multiple Sclerosis. PLoS ONE 2013;8:e67357.

11. Fera F, Passamonti L, Cerasa A, Gioia MC, Liguori M, Manna I et al. The BDNF Val66Met Polymorphism Has Opposite Effects on Memory Circuits of Multiple Sclerosis Patients and Controls. PLoS ONE 2013;8:e61063.

12. Inkster B, Strijbis EMM, Vounou M, Kappos L, Radue E-W, Matthews PM et al. Histone deacetylase gene variants predict brain volume changes in multiple sclerosis. Neurobiol Aging. 2013;34:238-47.
13. Vosslamber S, van der Voort LF, van den Elskamp IJ, Heijmans $\mathrm{R}$, Aubin $\mathrm{C}$, Uitdehaag BMJ et al. Interferon regulatory factor 5 gene variants and pharmacological and clinical outcome of Interferon $\beta$ therapy in multiple sclerosis. Genes Immun. 2011;12:466-72.

14. Sombekke $M H$, Vellinga MM, Uitdehaag BMJ, Barkhof $F$, Polman CH, Arteta D et al. Genetic Correlations of Brain Lesion Distribution in Multiple Sclerosis: An Exploratory Study. Am J Neuroradiol. 2011;32:695-703.

15. Ramasamy DP, Ramanathan M, Cox JL, Antulov R, Weinstock-Guttman B, Bergsland N et al. Effect of Met66 allele of the BDNF rs6265 SNP on regional gray matter volumes in patients with multiple sclerosis: A voxel-based morphometry study. Pathophysiology. 2011;18:53-60.

16. Weinstock-Guttman B, Benedict RHB, Tamaño-Blanco M, Ramasamy DP, Stosic M, Polito J et al. The rs2030324 SNP of brain-derived neurotrophic factor (BDNF) is associated with visual cognitive processing in multiple sclerosis. Pathophysiology. 2011;18:43-52.

17. Xia Z, Chibnik LB, Glanz BI, Liguori M, Shulman JM, Tran D et al. A Putative Alzheimer's Disease Risk Allele in PCK1 Influences Brain Atrophy in Multiple Sclerosis. PLOS ONE 2010;5:e14169.

18. Sombekke MH, Lukas C, Crusius JBA, Tejedor D, Killestein J, Arteta D et al. HLA-DRB $1 * 1501$ and Spinal Cord Magnetic Resonance Imaging Lesions in Multiple Sclerosis. Arch Neurol. 2009;66.

19. Baranzini SE, Wang J, Gibson RA, Galwey N, Naegelin Y, Barkhof $\mathrm{F}$ et al. Genome-wide association analysis of susceptibility and clinical phenotype in multiple sclerosis. Hum Mol Genet. 2009;18:767-78.

20. Zivadinov R, Weinstock-Guttman B, Benedict R, Tamano-Blanco M, Hussein S, Abdelrahman $\mathrm{N}$ et al. Preservation of gray matter volume in multiple sclerosis patients with the Met allele of the rs6265 (Val66Met) SNP of brain-derived neurotrophic factor. Hum Mol Genet. 2007;16:2659-68.

21. van Veen T, Nielsen J, Berkhof J, Barkhof F, Kamphorst W, Bö L et al. CCL5 and CCR5 genotypes modify clinical, radiological and pathological features of multiple sclerosis. J Neuroimmunol. 2007;190:157-64.

22. Kaimen-Maciel DR, Reiche EMV, Brum Souza DG, Frota Comini ER, Bobroff F, Morimoto HK et al. CCR5-Delta32 genetic polymorphism associated with benign clinical course and magnetic resonance imaging findings in Brazilian patients with multiple sclerosis. Int $\mathrm{J} \mathrm{Mol} \mathrm{Med.}$ 2007;20:337-44

23. Liguori M, Fera F, Gioia MC, Valentino P, Manna I, Condino $\mathrm{F}$ et al. Investigating the role of brain-derived neurotrophic factor in relapsing-remitting multiple sclerosis. Genes Brain Behav. 2007;6:177-83.

24. Wergeland S, Beiske A, Nyland $H$, Hovdal $H$, Jensen D, Larsen JP et al. IL-10 promoter haplotype influence on interferon treatment response in multiple sclerosis. Eur J Neurol. 2005;12:171-5.

25. Schrijver HM, Crusius JBA, García-González MA, Polman $\mathrm{CH}$, Peña AS, Barkhof $\mathrm{F}$ et al. Gender-Related Association Between the\&lt; \&gt; TGFB1\&lt;//\&gt;+869 Polymorphism and Multiple Sclerosis. J Interferon Cytokine Res. 2004;24:536-42.

26. Zwemmer JNP, Van Veen T, Van Winsen L, Van Kamp GJ, Barkhof F, Polman $\mathrm{CH}$ et al. No major association 
of ApoE genotype with disease characteristics and MRI findings in multiple sclerosis. Mult Scler. 2004;10:272-7.

27. Vanveen $T$, Crusius J, Vanwinsen $L$, Xia B, Barkhof $F$, Salvadorpena $A$ et al. CTLA-4 and CD28 gene polymorphisms in susceptibility, clinical course and progression of multiple sclerosis. J Neuroimmunol. 2003;140:188-93.

28. van Veen $T$, Kalkers $N$, Crusius JB, van Winsen $L$, Barkhof $F$, Jongen $P J$, et al. The FAS- 670 polymorphism influences susceptibility to multiple sclerosis. J Neuroimmunol. 2002;128:95-100.

29. Schreiber K, Oturai A, Ryder L, Madsen H, Jørgensen $\mathrm{O}$, Svejgaard A et al. Disease severity in Danish multiple sclerosis patients evaluated by MRI and three genetic markers (HLA-DRB1*1501, CCR5 deletion mutation, apolipoprotein E). Mult Scler. 2002;8:295-8.

30. Weatherby SJ, Mann CL, Davies MB, Fryer AA, Haq $\mathrm{N}$, Strange RC et al. A pilot study of the relationship between gadolinium-enhancing lesions, gender effect and polymorphisms of antioxidant enzymes in multiple sclerosis. J Neurol. 2000;247:467-70.

31. Kondo K. Abstracts of the $41^{\text {st }}$ annual meeting of the Japan society of human genetics October 23-25, 1996, Sapporo, Japan. Jpn J Hum Genet. 1997;42:23-167.
32. Przybek J, Gniatkowskal, Mirowska-Guzel D, Członkowska A. Evolution of diagnostic criteria for multiple sclerosis. Neurol Neurochir Pol. 2015;49:313-21.

33. Filippi M, Rocca MA, Ciccarelli O, De Stefano N, Evangelou N, Kappos L et al. MRI criteria for the diagnosis of multiple sclerosis: MAGNIMS consensus guidelines. Lancet Neurol. 2016;15:292-303.

Acceptance for editing: 2016-12-10 Acceptance for publication: 2016-12-22

Correspondence address: Prof. Jaroslaw Walkowiak, MD, PhD Department of Pediatric Gastroenterology and Metabolic Diseases

Poznan University of Medical Sciences 27/33 Szpitalna Street, 60-572 Poznan, Poland phone: +48 618491432 fax: +48618472685 email: jarwalk@ump.edu.pl 